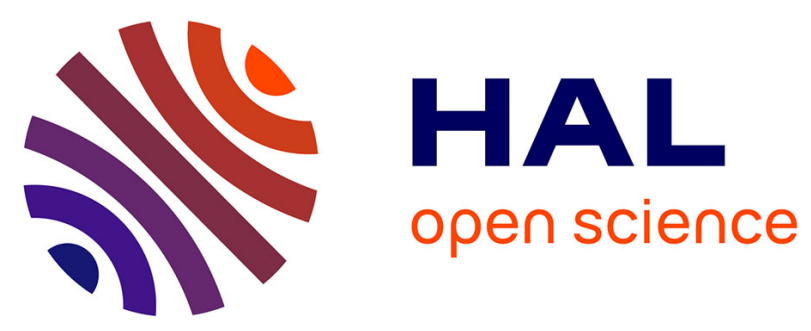

\title{
Aromatic and Terpenic Compounds Loaded in Lipidic Nanocapsules: Activity against Multi-drug Resistant Acinetobacter baumannii Assessed in vitro and in a Murine Model of Sepsis.
}

Angélique Montagu, Patrick Saulnier, Viviane Cassisa, Elisabeth Rossines, Matthieu Eveillard, Marie-Laure Joly-Guillou

\section{To cite this version:}

Angélique Montagu, Patrick Saulnier, Viviane Cassisa, Elisabeth Rossines, Matthieu Eveillard, et al.. Aromatic and Terpenic Compounds Loaded in Lipidic Nanocapsules: Activity against Multi-drug Resistant Acinetobacter baumannii Assessed in vitro and in a Murine Model of Sepsis.. Journal of Nanomedicine \& Nanotechnology, 2014, 5 (3), pp.206. 10.4172/2157-7439.1000206 . hal-03137651

\author{
HAL Id: hal-03137651 \\ https://univ-angers.hal.science/hal-03137651
}

Submitted on 10 Feb 2021

HAL is a multi-disciplinary open access archive for the deposit and dissemination of scientific research documents, whether they are published or not. The documents may come from teaching and research institutions in France or abroad, or from public or private research centers.
L'archive ouverte pluridisciplinaire HAL, est destinée au dépôt et à la diffusion de documents scientifiques de niveau recherche, publiés ou non, émanant des établissements d'enseignement et de recherche français ou étrangers, des laboratoires publics ou privés. 


\title{
Aromatic and Terpenic Compounds Loaded in Lipidic Nanocapsules: Activity against Multi-drug Resistant Acinetobacter baumannii Assessed in vitro and in a Murine Model of Sepsis
}

\author{
Montagu $A^{1,2,3 *}$, Saulnier $P^{1,2}$, Cassissa $V^{4}$, Rossines $E^{3}$, Eveillard $M^{4}$ and Joly-Guillou $M-L^{4}$ \\ ${ }^{1}$ LUNAM Université, F-49933 Angers, France \\ 2INSERM U1066, Micro et Nanomédecines Biomimétiques, IBS - CHU, 4 Rue Larrey, F-49933 Angers, France \\ ${ }^{3}$ Eydopharma, 5 allée des Grandes Bruyères, F-41200 Romorantin-Lanthenay, France \\ ${ }^{4}$ Laboratoire de microbiologie UPRESEA 3142, CHU Angers, 4 rue Larrey, 49033 Angers, France
}

\begin{abstract}
Given the spread of multidrug resistance and the number of antibiotics in development, finding new antibacterial strategies becomes necessary. One of these strategies is to use extracts of essential oils that are a potential reservoir of effective antibacterial molecules. The objective of the study was to evaluate the possibility of administering to animal, mixtures of carvacrol and eugenol (phenols), cinnamaldehyde (aldehyde) and/or $\beta$-caryophyllene (alkene) encapsulated in lipid nanocapsules to provide an optimal bio distribution and antimicrobial efficacy. These suspensions were tested in vitro and the results showed an important antibacterial activity against A. baumannii, a multidrugresistant microorganism responsible for outbreaks in intensive care units, similar to the activity of non-encapsulated mixtures. Subsequently, the suspensions activities were assessed with a murine model of sepsis using the same $A$. baumannii strain. These preliminary results showed a mice survival varying from $45 \%$ to $55 \%$. It is the first time that antimicrobial essential oils can be administered intraperitonneally via nanomedicine. These results are encouraging and further studies are needed to pursue the development of this strategy.
\end{abstract}

Keywords: Gram-negative bacteria; Phenols; Aldehydes; Lipid nanocapsules; In vivo efficacy

\section{Introduction}

The abusive utilization of antibiotics in many areas promoted the emergence of multidrug resistant bacteria (MRB) including Acinetobacter baumannii, a pathogen responsible for outbreaks in intensive care units. During the last decade, A. baumannii has emerged as a major cause of both community-associated and worldwide nosocomial infections [1]. These bacteria can adapt very quickly and can develop various mechanisms of resistance: production of $\beta$-lactamases, efflux pumps, lower permeability of the outer membrane ( $\beta$-lactams), mutations in antibiotic targets (quinolones) and production of enzymes inactivating aminoglycosides [2,3]. These mechanisms associated with the ability of bacteria to integrate foreign genetic material can transform them in highly resistant bacteria $[2,4]$. This micro-organism is responsible for up to $10 \%$ of all Gram-negative bacterial infections in intensive care units in Europe and the USA [4]. Moreover, recent microbiological surveillance trials in USA realized by Halstead [5] showed rates of multidrug resistance in A. baumannii of approximately $30 \%$. In recent years, pharmaceutical industry has focused on the development of new antibiotics targeting multi-resistant Gram-positive bacteria as methicillin-resistant Staphylococcus aureus (MRSA). In contrast, the industrial development of new molecules active against multi-resistant Gram-negative bacteria has been very limited. So, given the spread of the antibiotic resistance phenomenon of these bacteria and a limited number of antibiotics in development, it is urgent to find out novel antibacterial strategies. Some natural resources, especially essential oils (EOs), appear to constitute a potential reservoir of several effective antimicrobial molecules [6-8]. The major components of EO are divided in two groups according to their very distinct biosynthesis pathways: compounds from terpene origin and aromatic compounds which present the highest antibacterial activity compared to other terpenoid classes $[7,9]$. The EO antimicrobial activity is mostly due to the presence of aromatic molecules such as phenols (carvacrol, eugenol) or aldehydes (cinnamaldehyde). These three active components have been demonstrated to present a significant activity against a number of Gram-positive and Gram-negative bacteria $[7,8]$ including Acinetobacter species [10-12]. Several studies underlined the interest of the combination of antimicrobial agents which can provide a synergic effect in order to limit the risk of emergence of MRB. Few studies tested the inhibitory effect of natural antibacterial mixtures with carvacrol and eugenol [13-15] cinnamaldehyde $[16,17]$ and $\beta$-caryophyllene [18] against several bacteria.

However, these components are very poorly soluble in water and their injection into the bloodstream is difficult as they stand. In most of the cases, they need to be administered by oral route or topically. Unfortunately, they tend to bind to the bolus hydrophobic components resulting in a decrease of their bioavailability and therefore their antimicrobial activities in vivo [19,20]. This characteristic behavior requires the use of an appropriate system presenting hydrophilic characteristics to enhance the hydrodispersity. The encapsulation of these three components could be more interesting to increase antimicrobial effectiveness by promoting contact with the bacterial cells. Thus, different colloidal systems have been developed as drug delivery ones such as emulsions [11,21-25], micelles [20,26,27] and mostly nanoparticles (NPs) [28-36]. However, these NPs present many

*Corresponding author: Angélique Montagu, INSERM U1066, Micro et Nanomédecines Biomimétiques, IBS - CHU, 4 Rue Larrey, F-49933 Angers, France, Tel: +33244688567; E-mail: angelique.montagu@gmail.com

Received May 26, 2014; Accepted June 13, 2014; Published June 17, 2014

Citation: Montagu A, Saulnier P, Cassissa V, Rossines E, Eveillard M, et al. (2014) Aromatic and Terpenic Compounds Loaded in Lipidic Nanocapsules: Activity against Multi-drug Resistant Acinetobacter baumannii Assessed in vitro and in a Murine Model of Sepsis. J Nanomed Nanotechnol 5: 206. doi: 10.4172/21577439.1000206

Copyright: () 2014 Montagu A, et al. This is an open-access article distributed under the terms of the Creative Commons Attribution License, which permits unrestricted use, distribution, and reproduction in any medium, provided the original author and source are credited. 
drawbacks such as using an inherent solvent or the need of high energy process for their manufacturing. In this context, an interesting type of NPs, the lipidic nanocapsules (LNCs) are suitable for the encapsulation of lipophilic active compounds. Their preparation (soft energy method process) does not require the use of organic solvents. Moreover, they are prepared at low cost and can be transposable [37].

The present research focused on the production and characterization of LNCs loaded with actives mixtures (eugenol, carvacrol, cinnamaldehyde and $\beta$-caryophyllene). The antimicrobial activity of these nano-delivery systems was evaluated in vitro against A. baumannii in order to validate or not a synergic effect due to the differents active in the mixtures presented inside a nanoparticle. Finally, a preliminary in vivo study of these formulations was tested by using a mice model of sepsis.

\section{Materials and Methods}

\section{Chemicals materials}

5-Isopropyl-2 methylphenol (Carvacrol, $\mathrm{Ca} \geq 98 \%$ ) and $\beta$-Caryophyllene ( $\beta \mathrm{C} \geq 98.5 \%)$ were purchased from Sigma-Aldrich (Saint-Louis, USA). Trans-Cinnamaldéhyde $(\mathrm{Ci} \geq 98 \%)$ and eugenol ( $\mathrm{Eu} \geq 99 \%)$ were purchased from Merck-Millipore (Molsheim, France). The lipophilic Labrafac" WL1349 ("caprylic-capricacidtriglycerides") was purchased from Gattefosse S.A. (Saint-Priest, France). Lipoïd S753 (soybean lecithin at $69 \%$ of phosphatidylcholine) came from Lipoïd Gmbh (Ludwigshafen, Germany); Kolliphor HS15 (a mixture of free polyethylene glycol 660 and polyethylene glycol 660 hydroxystearate from BASF (Ludwigshafen, Germany) and $\mathrm{NaCl}$ from Prolabo (Fontenay-sous-bois, France). Deionized water was acquired from a Milli-Q plus system (Millipore, Paris, France) and sterile water from Cooper (Melun, France).

\section{Preparation of LNCs loaded with mixtures of EO components}

LNCs were prepared according to the original described procedure [38]. Briefly, the formulation consisted on the mixing of all the components (Kolliphor HS15 (4.70\% w/w), Labrafac WL1349 (5.70\% w/w), Lipoid S75-3 (0.41\% w/w), $\mathrm{NaCl}(0.5 \% \mathrm{w} / \mathrm{w})$ and deionized water $(16.43 \% \mathrm{w} / \mathrm{w}))$ under magnetic stirring and heating from room temperature to $90^{\circ} \mathrm{C}$. Two cycles of progressive cooling and heating between $90^{\circ} \mathrm{C}$ and $60^{\circ} \mathrm{C}$ were then carried out to homogenize the mixture. Then, active compounds were added to the mixture at different cycles according to their phase inversion temperature (PIT) [38]. Finally, an irreversible shock induced by a sudden dilution of the mixture with cold water $(69.36 \% \mathrm{w} / \mathrm{w})$ was performed according to the PIT of the mixture. Slow magnetic stirring was then applied to the suspension for $5 \mathrm{~min}$. Three formulations were prepared. The first one (F1) concerned the incorporation of carvacrol $(0.96 \% \mathrm{w} / \mathrm{w})$, eugenol $(0.96 \% \mathrm{w} / \mathrm{w})$ and cinnamaldehyde $(0.96 \% \mathrm{w} / \mathrm{w})$ in LNCs. The second one (F2) was prepared by the incorporation of carvacrol $(0.34 \% \mathrm{w} / \mathrm{w})$, eugenol $(1.83 \% \mathrm{w} / \mathrm{w}), \beta$-caryophyllene $(0.32 \% \mathrm{w} / \mathrm{w})$ and cinnamaldehyde $(0.39 \% \mathrm{w} / \mathrm{w})$ in LNCs (Table 1$)$. LNCs were at a final concentration of $28.5 \mathrm{mg}$ of actives per $\mathrm{ml}$ of LNCs suspension. The third formulation was represented by active-unloaded LNCs (blank LNCs).

\section{Determination of encapsulation efficiency}

The efficiency of the encapsulation was determined by ultracentrifugation at $100000 \mathrm{rpm}$ during 1 hour at $4^{\circ} \mathrm{C}$. The drug loading capacity [39] and the encapsulation efficiency (EE)

\begin{tabular}{|l|c|c|c|}
\hline \multicolumn{1}{|c|}{ Constituents } & Among (g) & & \\
\cline { 2 - 4 } & Blank LNCs & Ca-Eu-Ci - LNCs 1 & Ca-Eu-Ci- $\beta$ C-LNCs 2 \\
\hline Kolliphor $^{\circledR}$ HS15 & 0.846 & 0.846 & 0.846 \\
\hline Labrafac $^{\circledR}$ WL1349 & 1.028 & 1.028 & 1.028 \\
Lipoid $^{\circledR}$ S75-3 & 0.075 & 0.075 & 0.075 \\
\hline $\mathrm{NaCl}$ & 0.089 & 0.089 & 0.089 \\
\hline $\begin{array}{l}\text { Deionized water } \\
\text { Deionized water } \\
\text { at 2 }{ }^{\circ} \mathrm{C}\end{array}$ & 2.962 & 2.962 & 2.962 \\
\hline Actives & 12.5 & 12.5 & 12.5 \\
\hline
\end{tabular}

Table 1: Composition of blank LNCs, Ca-Eu-Ci - LNCs 1 and Ca-Eu-Ci-BC-LNCs 2.

were determined for both formulations [39]. So, DL\% and EE\% of formulations were then determined as follows:

$\mathrm{DL} \%=$ weight of actives mixtures in LNC/weight of actives mixtures in LNC + weight of raw material

$\mathrm{EE} \%=$ weight of actives mixtures in LNC/weight of actives mixtures used

\section{LNC Characterization}

The determination of the drug loading in LNCs was achieved by spectro-photometry (UV-2600, Shimadzu, Noisiel, France) at 293nm (for F1) and 283nm (for F2) after dilution of the whole suspension at $1: 1000(\mathrm{v} / \mathrm{v})$ in methanol (Fisher chemical) after and before ultracentrifugation. The calibration curve, ranged to from $10 \mu \mathrm{g} / \mathrm{ml}$ to $100 \mu \mathrm{g} / \mathrm{ml}$, was also prepared in methanol. The average hydrodynamic diameter and the polydispersity index (PdI) [40] of nanocapsules were determined at $25^{\circ} \mathrm{C}$, in triplicate, by using a Malvern Zetasizer (Nano Serie DTS 1060, Malvern Instruments S.A., Worcestershire, UK). For the measurements, the LNC suspensions were diluted at 1:60 (v/v) in deionized water.

\section{Determination of antibacterial activity}

The antibacterial effects of LNCs loaded with active mixtures and the antibacterial effects of pure active mixtures were evaluated by using two parameters: the minimal inhibitory concentrations (MICs) and bactericidal kinetics. In the study, we used Acinetobacter baumannii (SAN-94040), a cephalosporinase-overproducing strain resistant to most $\beta$-lactams, to aminoglycosides and fluoroquinolones. It was isolated from the blood culture of a patient from North Africa (Algeria) who presented a nosocomial pneumonia. For the determination of the MICs, this bacterial suspension with a turbidity equivalent to a McFarland 0.5 standard were prepared $\left(10^{8} \mathrm{CFU} / \mathrm{ml}\right)$ in broth liquid medium. The solution was diluted in brain heart infusion $(\mathrm{BHI}$, bioMerieux, Marcy l'Etoile, France). Briefly, in each well of a 96 well plate, serial dilutions of free actives and active mixtures (carvacrol, eugenol, cinnamaldehyde or $\beta$-caryophyllene) or LNCs loaded with actives at concentrations from $0.08 \mathrm{mg} / \mathrm{ml}$ to $5 \mathrm{mg} / \mathrm{ml}$ were used in the presence of bacterial suspensions. The control constituted of bacteria without actives. After 24 -hour incubation at $37^{\circ} \mathrm{C}$, the different MIC values were determined as the lowest concentration of the antimicrobial active that inhibited the visible growth of the microorganism tested.

The bactericidal kinetics were studied at twice MICs in BHI. The times of measurement of the bacterial counts were 0 hour, 3 hours, 6 hours and 24 hours after incubation at $37^{\circ} \mathrm{C}$. At each time, bacterial suspensions were plated on Columbia agar with sheep blood $(\mathrm{GmbH}$, 
Citation: Montagu A, Saulnier P, Cassissa V, Rossines E, Eveillard M, et al. (2014) Aromatic and Terpenic Compounds Loaded in Lipidic Nanocapsules: Activity against Multi-drug Resistant Acinetobacter baumannii Assessed in vitro and in a Murine Model of Sepsis. J Nanomed Nanotechnol 5: 206. doi: 10.4172/2157-7439.1000206

Page 3 of 7

Wesel, Germany). Next, colonies were counted. Each bacterial count was performed in triplicate.

The toxicity of the blood cells was evaluated at twice MICs in defibrinated horse blood (Oxoid, Dardilly, France). The times of observation were 0 hour, 3 hours, 6 hours and 24 hours after incubation at $37^{\circ} \mathrm{C}$. At each time, an estimation of blood cells survival was realized. Moreover, there is no rupture of red blood cells after 6 hours of contact with active pure mixtures and active pure mixture-loaded LNCs at CMI twice (data not shown).

All in vitro experiments were performed at least three times in independent conditions.

\section{In vivo experiments}

Animals: Six-week old females $\mathrm{C} 3 \mathrm{H} / \mathrm{HeN}$ mice (18-20 g) (Elevage Janvier, Sarthe, France) were used for the experimental sepsis model. They were housed 5 per cage and had access to chow and water ad libitum throughout the experiments. All the experiments were performed according to the European ethic regulation on animal models. The in vivo study protocol was approved by the National Ethic Committee of the French Ministry of Health under Number-00751.1. The authors state that there was no alternative to animal experiments in this work and that all ethical rules of humane care of animals were observed.

Sepsis model: A. baumannii bacterial suspensions were prepared in order to obtain a turbidity equivalent to a McFarland 0.5 standard $\left(10^{8} \mathrm{CFU} / \mathrm{ml}\right)$. Formulations were diluted in saline to obtain a 40 $\mathrm{mg} / \mathrm{kg}$ regimen, which was injected in two steps. At T0, $100 \mu \mathrm{l}$ of two formulations were injected intraperitoneally. After 3 hours, the second injection of formulations and the injection of the bacterial suspension were performed simultaneously. The bacterial suspension was inoculated at the opposite side of the treatment injection. Mice were monitored during 96 hours for survival rates. Groups of 20 mice were used for each experiment condition. All in vivo experiments were performed four times for each condition (control, F1 and F2).

\section{Results}

\section{Physicochemical properties of LNC suspensions}

Blank LNCs presented an average hydrodynamic diameter of $50 \pm$ $3 \mathrm{~nm}$ and a very narrow size polydispersity $(\mathrm{PdI}=0.07)$ showing a very low heterogeneity in the suspension (Table 2).

Both formulations presented characteristics strongly dependent on the concentration of active molecules. At first they presented a size increase compared to blank LNCs. Concurrently, an increase of zeta potential (ZP) was observed for active-loaded-LNCs compared to blank LNCs (Table 2).

$\mathrm{Ca}-\mathrm{Eu}-\mathrm{Ci}$ - LNCs were more stable in terms of size increase versus time in comparison with Ca-Eu-Ci- $\beta \mathrm{C}$ - LNCs. Indeed, these LNCs presented a size increase in the range $20-40 \mathrm{~nm}$ according to the batches whereas Ca-Eu-Ci - LNCs kept the same size during many weeks.

The theoretical concentration of both formulations was 28.5 $\mathrm{mg} / \mathrm{ml}$. After an UV spectrophotometer study, the effective LNCs concentrations were $30.7 \mathrm{mg} / \mathrm{ml}, 29.6 \mathrm{mg} / \mathrm{ml}$ for F1 and F2 formulations respectively.

The EE was $86 \%$ for $\mathrm{F} 1$ whereas it was $49 \%$ for $\mathrm{F} 2$. The DL was $20 \%$ for both formulations. Moreover, the size of LNCs-suspension was not modified after ultracentrifugation.

\section{Antibacterial activity of formulations}

The MICs values of free actives, free active mixtures and active loaded LNCs against $A$. baumannii are presented on Table 3 .

The results showed that the mixture or free actives and LNCs loaded with actives had MICs of 0.31 to $1.25 \mathrm{mg} / \mathrm{ml}$ against $A$. baumannii except for unloaded-LNCs which presented a MIC above $5 \mathrm{mg} / \mathrm{ml}$. The results showed that eugenol had the highest MIC among free actives. When eugenol was mixed with cinnamaldehyde (1:1) or carvacrol (1:1), a decrease of the MIC at $0.31 \mathrm{mg} / \mathrm{ml}$ was observed. The same results are obtained for mixtures with three or four actives with MICs of $0.31-0.62 \mathrm{mg} / \mathrm{ml}$. Furthermore, no difference was noted between MICs of active mixtures and nano-encapsulated active mixtures. The MIC was of $0.31 \mathrm{mg} / \mathrm{ml}$ for Ca-Eu-Ci mixtures and Ca-Eu-Ci-LNCs and $0.62 \mathrm{mg} / \mathrm{ml}$ for Ca-Eu-Ci- $\beta \mathrm{C}$ mixtures and Ca-Eu-Ci- $\beta$ C LNCs. So, the addition of $\beta$-caryophyllene was not responsible for an antagonistic effect. Both formulations and actives mixtures were evaluated by kinetic bactericidal assays (Figure 1).

The bactericidal kinetic assays showed comparable results for active mixtures as they were bacteriostatic or bactericide from 3 hours to 24 hours following the beginning of the experiences. In a same way, the active-loaded LNCs had the same bactericidal kinetics profiles as they were bacteriostatic from 3 hours to 24 hours following the beginning of the experiences. These results underlined a stronger antibacterial effect concerning active mixtures.

\section{Survival studies}

After showing in vitro antibacterial abilities, these formulations were tested in an in vivo model of sepsis in mice in order to estimate the efficacy of the related loaded suspensions against $A$. baumannii

\begin{tabular}{|c|c|c|c|c|c|c|}
\hline & Particle size (nm) & Polydispersity & Zeta potential $(\mathrm{mV})$ & $\begin{array}{l}\text { Drug loading } \\
\text { capacity }(\mathbf{m g} / \mathbf{g})\end{array}$ & $\begin{array}{c}\text { Concentration (mg/ } \\
\mathrm{ml})\end{array}$ & $\begin{array}{c}\text { Encapsulation } \\
\text { efficiency }(\mathrm{mg} / \mathrm{ml})\end{array}$ \\
\hline Unloaded-LNCs & $50 \pm 3$ & $0.07 \pm 0.02$ & $-8 \pm 1.2$ & - & - & - \\
\hline Ca-Eu-Ci - LNCs 1 & $90 \pm 5$ & $0.09 \pm 0.04$ & $-20 \pm 3$ & $20 \%(1: 1: 1)$ & 30.7 & $86 \%$ \\
\hline Ca-Eu-Ci- $\beta C$-LNCs 2 & $66 \pm 4$ & $0.12 \pm 0.004$ & $-16 \pm 2$ & $20 \%(1: 6: 1: 1)$ & 29.6 & $49 \%$ \\
\hline
\end{tabular}

Table 2: Characteristics of formulations (data are expressed as mean $\pm \mathrm{SD}$ )

\begin{tabular}{|c|c|c|c|c|c|c|c|}
\hline & Eugenol & Carvacrol & Cinnamaldehyde & Eu-Ci (1:1) & Eu-Car (1:1) & Ca-Eu-Ci (1:1:1) & Ca-Eu-Ci- $\beta C(1: 6: 1: 1)$ \\
\hline $\mathrm{MIC}(\mathrm{mg} / \mathrm{ml})$ & $1.25 \pm 0.01$ & $0.31 \pm 0.01$ & $0.31 \pm 0.01$ & $0.31 \pm 0.01$ & $0.31 \pm 0.01$ & $0.31 \pm 0.01$ & $0.62 \pm 0.01$ \\
\hline & & \multicolumn{2}{|c|}{ Unloaded-LNCs } & \multicolumn{2}{|c|}{ Ca-Eu-Ci-LNCs F1 } & \multicolumn{2}{|c|}{ Ca-Eu-Ci-ßBC-LNCs F2 } \\
\hline $\mathrm{MIC}(\mathrm{mg} / \mathrm{ml})$ & & \multicolumn{2}{|c|}{$\geq 5 \pm 0.01$} & \multicolumn{2}{|c|}{$0.31 \pm 0.01$} & \multicolumn{2}{|r|}{$0.62 \pm 0.01$} \\
\hline
\end{tabular}

Table 3: MICs of pures actives, pures actives mixtures and Ca-Eu-Ci-LNCs F1, Ca-Eu-Ci- $\beta$ car-LNCs F2 against $A$. baumannii. 
infections (Figure 2).

The results of the sepsis model showed that F1 and F2 induced an increase of the mice survival after the 96-hour follow-up (55\% and $45 \%$ respectively) as compared to the control group. Due to the small animal amounts, no significant statistical differences can be noticed between F1 and F2. Perhaps, the tendency (in favor of F1) could be explained by different encapsulation efficiencies (F1 have a higher rate of loading compared to F2).

\section{Discussion}

Antimicrobial resistance is one of the most serious threats concerning healthcare today since MDR bacteria are more and more prevalent worldwide. Concurrently, the pharmaceutical industry is not producing new antibiotics. This lack of availability of new antibiotics is particularly pregnant for Gram-negative organisms. Therefore, envisaging new alternatives is becoming necessary now. To our knowledge, this is the first report where combinations of EO extracted from plant are used in nanomedecine. Indeed, EOs are known to have a strong antibacterial potential and this biological activity is mainly due to their composition including aromatic and terpenic compounds $[7,8]$. So, EOs of spices and herbs such as origanum, cinnamon, clove have the strongest antibacterial properties because of their major components which are carvacrol, cinnamaldehyde and eugenol respectively [9].

Cinnamaldehyde is an aldehyde which presents an important

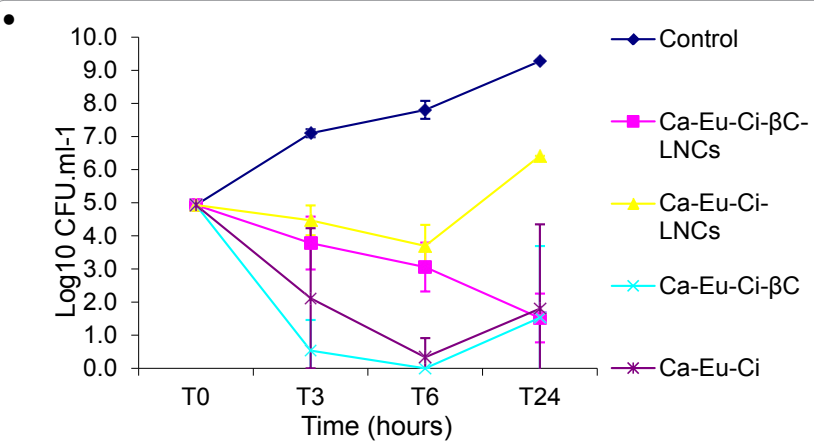

Figure 1: Bactericidal kinetics of actives mixtures and corresponding encapsulated mixtures against $A$. baumannii (twice MIC).

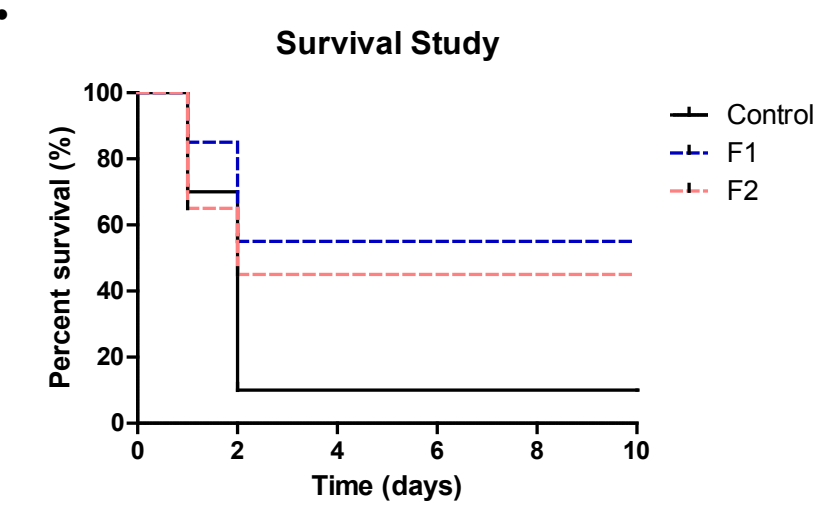

Figure 2: Survival curves of mice infected with $A$. baumannii in a sepsis model Three groups are presented; one control group $(n=20)$, a group treated with carvacrol, eugenol and cinnamaldehyde loaded-LNC $(n=20)$ and a group treated with carvacrol $(0.34 \% \mathrm{w} / \mathrm{w})$, eugenol $(1.83 \% \mathrm{w} / \mathrm{w}), \beta$-caryophyllene $(0.32 \% \mathrm{w} / \mathrm{w})$ and cinnamaldehyde $(0.39 \% \mathrm{w} / \mathrm{w})$ loaded-LNC $(n=20)$. antibacterial activity through this carbonyl group which binds to proteins [8]. However, it is not able to disorganize the outer cell membrane or deplete the intracellular ATP pool [41]. Carvacrol and eugenol are phenolic compounds, which are able to disrupt the membrane structure by inserting in this one by the way of their hydroxyl group $[42,43]$. In addition, this phenomenon causes a decrease of intracellular ATP and membrane potential. It also causes leakage of different substances such as ions, ATP, amino acids and nucleic acids leading to the bacterial death.

For this study, we have selected these components considering their antibacterial activity and we have associated them with the aim of obtaining an optimized antibacterial action. Assessing the effectiveness of different antimicrobial agents is interesting when considering the risk of selecting resistant mutants inside the initial bacterial population by using conventional doses of a single antimicrobial agent.

In a previous study, the product tested showed a very significant antibacterial activity against bacteria from very diverse clinical samples [44]. These products were effective whatever the resistance phenotype expressed towards antibiotics and a wide spectrum of bacterial species. These observations led us to choose Acinetobacter as the main specie test in the following studies.

We have encapsulated this mixture by using LNCs since the encapsulation of actives could improve the active mixtures bioavailability and the antimicrobial activity in vivo. Moreover, LNCs increase the antimicrobial efficacy by their subcellular size promoting a specific contact with bacterial cells [45].

The development has been complicated due to interactions established between the molecules and the importance of maintaining the synergies between these antibacterial molecules.

The two formulations presented different characteristics in LNC suspensions (Table 2). Indeed, the size of $\mathrm{Ca}-\mathrm{Eu}-\mathrm{Ci}$ - LNCs was higher than the size of $\mathrm{Ca}-\mathrm{Eu}-\mathrm{Ci}-\beta \mathrm{C}$ - LNCs. The size of carvacrol-loadedLNCs was $85.2 \pm 4.6 \mathrm{~nm}$ whereas the sizes of eugenol-loaded-LNCs and cinnamaldehyde-loaded-LNCs were $45.2 \pm 1.9 \mathrm{~nm}$ and $64.9 \pm 1.9 \mathrm{~nm}$ respectively (data not shown). As, Ca-Eu-Ci - LNCs had the highest concentration of carvacrol $(0.96 \% \mathrm{w} / \mathrm{w})$ of the two formulations, and as $\mathrm{Ca}-\mathrm{Eu}-\mathrm{Ci}-\beta \mathrm{C}-\mathrm{LNCs}$ had the highest rate of eugenol $(1.83 \% \mathrm{w} / \mathrm{w})$, this result was not surprising.

The results showed that after its incorporation in the process, the $\beta$-caryophyllene, did not increase the LNCs size compared to the F1. This active was mainly used to increase the synergy between carvacrol, eugenol and cinnamaldehyde, it had not any antibacterial efficacy but it presented anti-inflammatory and anti-oxidant properties [46,47]. It is noteworthy that the addition of $\beta$-caryophyllene modified the PIT of the LNC-suspensions.

Among the actives, cinnamaldehyde have higher surfactant properties. Indeed, the PIT of the cinnamaldehyde-LNCs is around $45^{\circ} \mathrm{C}$ whereas it is around $82^{\circ} \mathrm{C}$ for LNCs blank (data not shown), Therefore, the presence of cinnamaldehyde could modify the ZP. This phenomenon could underline a modification of the LNC surface. It can be hypothesized that the spatial conformation of the PEG chains was modified and that the presence of active molecules at the surface resulted to more negative $\mathrm{ZP}$ as compared to unloaded LNCs. So, even though the active compounds were mainly lipohilic, they were distributed between the core and the shell depending upon their solubility or dispersibility as well as their more or less pronounced amphiphilic properties. Indeed, the molecules that can preferentially 
Citation: Montagu A, Saulnier P, Cassissa V, Rossines E, Eveillard M, et al. (2014) Aromatic and Terpenic Compounds Loaded in Lipidic Nanocapsules: Activity against Multi-drug Resistant Acinetobacter baumannii Assessed in vitro and in a Murine Model of Sepsis. J Nanomed Nanotechnol 5: 206. doi: 10.4172/2157-7439.1000206

target the shell are able to modify the surface properties and thus the ZP.

In our study, the antimicrobial activities of eugenol, carvacrol, cinnamaldehyde, two-compound, three-compound and fourcompound mixtures were evaluated by MICs for determining a synergistic effect against $A$. baumannii (Table 3). The combination of eugenol with carvacrol or cinnamaldehyde promoted a synergic effect. This synergism has already been described in various studies [14,47]. The lower antibacterial activity of eugenol could be attributed to a lower hydrophobicity of the methoxyl group in ortho position on the ring [48]. A study conducted by Pei et al. [17] showed that eugenol MICs against E. coli decreased from $1.6 \mathrm{mg} / \mathrm{ml}$ to $0.4 \mathrm{mg} / \mathrm{ml}$ with cinnamaldehyde and from $1.6 \mathrm{mg} / \mathrm{ml}$ to $1 \mathrm{mg} / \mathrm{ml}$ with carvacrol.

Moreover, we noted that MICs of the different mixtures were comparable, with values comprised between $0.31 \mathrm{mg} / \mathrm{ml}$ and $0.62 \mathrm{mg} /$ $\mathrm{ml}$. In our case, the synergistic two-compound mixtures contributed to the synergistic effects recorded in the three-compound and the four-compound mixtures. However, it seems difficult to anticipate the effects of interactions (synergistic, additive, or antagonist effect) in combination of antimicrobial actives against other bacterial strains $[46,49]$. Moreover, the efficacy will not be the same according to bacterial species. For example, the wall of Gram-positive bacteria is more difficult to disrupt because of the thickness of their peptidoglycan layer. Indeed, Hill et al. [47] noted that Listeria innocua is more resistant to antibacterial active mixtures and nano-encapsulated mixtures as compared to Salmonella typhimurium.

MICs of active mixtures were compared to MICs of active mixtures included in LNCs at the same concentrations (Table 3). In our study, there was no difference about their MICs. So, we concluded that there was no loss of antibacterial efficacy when active pure mixtures were nano-encapsulated (Figure 1). Some other studies reported the same phenomenon concerning the continued effectiveness of actives after the encapsulation procedure. For instance, a study conducted by Keawchaoon and Yoksan [32] demonstrated that MICs of free carvacrol and carvacrol-loaded chitosan-NPs against Escherichia coli, S. aureus and Bacillus cereus were similar. Hill et al. [47] demonstrated that MICs of cinnamaldehyde-eugenol (2:1) and cinnamaldehyde-eugenol (2:1) $\beta$ cyclodextrine inclusion complexes against $S$. typhimurium were 0.5 $\mathrm{mg} / \mathrm{ml}$ and $0.48 \mathrm{mg} / \mathrm{ml}$ respectively. In another study, Chen et al. [28] showed that the MIC of eugenol chitosan-NPs was lower than the MIC of pure eugenol against $E$. coli and S. aureus.

In the present study, Acinetobacter baumannii was used to test the effectiveness of these products in an in vivo model because of its multiresistance to antibiotics $[3,50]$. The sepsis model used was interesting for its execution speed and its simplicity. Despite, it was certainly less relevant than some more specific models like the experimental model of pneumonia developed in our laboratory $[1,51]$, it allowed to assess the in vivo efficacy without needing a large number of animals.

In our study, two types of LNC suspensions were able to eradicate A. baumannii infection in a preliminary in vivo model of sepsis in mice (Figure 2). These results underline the efficacy of those drugs to combat this systemic infection. This efficacy showed the potential of hydrophilic surfactant, Kolliphor HS15 ${ }^{\circ}$ (70\% PEG660 hydroxystearate and $30 \%$ free PEG660) conferring long-time-circulating properties of LNCs. Indeed, a study of Ballot et al. [52] showed that the time of the systemic circulation of LNCs or radionuclide-loaded-LNCs was increased as compared to the time of systemic circulation of free radionuclides. In addition, Vonarbourg et al. [45] showed very low complement activation and macrophage uptake due to the high density of PEG on the LNC surface.

However, this antibacterial efficacy in our in vivo model was not optimal and it would be interesting to use various strategies for improve the LNC efficacy. One of those strategies would be to improve the LNC presence in the bloodstream, for instance by modifying the surface of the LNC. Several studies underlined the use of post-inserted LNCs for increasing the systemic circulation time in bloodstream. For example, a study conducted by Morille et al. [53] showed the greatest persistence time of DSPE-PEG2000-LNCs compared to empty LNCs (1.5h for empty LNC versus $7.1 \mathrm{~h}$ for DSPE-PEG2000 10mM). Another approach would be to modify LNCs in order to be more specific about targeting the bacterial cells. For example, using the chitosan or silver for producing LNCs [34,35,54-56] would confer to them a positive charge. This charge could allow a best interaction with negatively charged bacterial cell wall. This interaction could lead to the leakage of the intracellular components in the in vitro and in vivo models. An innovative strategy was demonstrated by Mihu et al. [57] underlining the therapeutic potential of nitric oxide-NPs in an A. baumannii wound infection model. As the nitric oxide modulates immune responses and modifies wound healing, the treatment with NO-nanoparticles significantly accelerated healing of infected wounds.

\section{Conclusion}

Our strategy seems to be an alternative to antibiotics to combat $A$. baumannii systemic infections. Moreover, it is the first time that a study is presented from the development of molecules until the evaluation of in vitro and in vivo efficacies, allowing to shorten the study time of effective antibacterial component. Indeed, this study underlined the proof of concept of a new antibacterial treatment which used the vectorization by LNCs of a combination of potent antibacterial components. So, this study could maybe serve as a model for other bacteria and it could represent the first step for the development of new therapeutics for the treatment of MDR bacteria infections.

\section{References}

1. Eveillard M, Soltner C, Kempf M, Saint-André JP, Lemarié C, et al. (2010) The virulence variability of different Acinetobacter baumannii strains in experimental pneumonia. J Infect 60: 154-161.

2. Karageorgopoulos DE, Falagas ME (2008) Current control and treatment of multidrug-resistant Acinetobacter baumannii infections. Lancet Infect Dis 8: 751-762.

3. McConnell MJ, Actis L, Pachón J (2013) Acinetobacter baumannii: human infections, factors contributing to pathogenesis and animal models. FEMS Microbiol Rev 37: 130-155

4. Cristina ML, Spagnolo AM, Cenderello N, Fabbri P, Sartini M, et al. (2013) Multidrug-resistant Acinetobacter baumannii outbreak: an investigation of the possible routes of transmission. Public Health 127: 386-391.

5. Halstead DC, Abid J, Dowzicky MJ (2007) Antimicrobial susceptibility among Acinetobacter calcoaceticus-baumannii complex and Enterobacteriaceae collected as part of the Tigecycline Evaluation and Surveillance Trial. J Infect 55: 49-57.

6. Bajpai VK, Baek KH, Kang SC (2012) Control of Salmonella in foods by using essential oils: A review. Food Research International 45: 722-734.

7. Bakkali F, Averbeck S, Averbeck D, Idaomar M (2008) Biological effects of essential oils--a review. Food Chem Toxicol 46: 446-475.

8. Burt S (2004) Essential oils: their antibacterial properties and potential applications in foods--a review. Int J Food Microbiol 94: 223-253.

9. Kalemba D, Kunicka A (2003) Antibacterial and antifungal properties of essential oils. Curr Med Chem 10: 813-829.

10. Chiaradia V, Paroul N, Cansian RL, Júnior CV, Detofol MR, et al. (2012) 
Citation: Montagu A, Saulnier P, Cassissa V, Rossines E, Eveillard M, et al. (2014) Aromatic and Terpenic Compounds Loaded in Lipidic Nanocapsules: Activity against Multi-drug Resistant Acinetobacter baumannii Assessed in vitro and in a Murine Model of Sepsis. J Nanomed Nanotechnol 5: 206. doi: 10.4172/2157-7439.1000206

Synthesis of eugenol esters by lipase-catalyzed reaction in solvent-free system. Appl Biochem Biotechnol 168: 742-751.

11. Liang M, Yang CH, Li ST, Yang CS, Chang HW, et al. (2008) Antibacteria and antioxidant properties of Ramulus Cinnamomi using supercritical $\mathrm{CO}_{2}$ extraction. European Food Research and Technology 227: 1387-1396.

12. Mahmoud BSM, Yamazaki K, Miyashita K, Shik SI, Dong-Suk C, et al. (2004) Bacterial microflora of carp (Cyprinus carpio) and its shelf-life extension by essential oil compounds. Food Microbiology 21: 657-666.

13. Chan AC, Ager D, Thompson IP (2013) Resolving the mechanism of bacterial inhibition by plant secondary metabolites employing a combination of wholecell biosensors. J Microbiol Methods 93: 209-217.

14. García-García R, López-Malo A, Palou E (2011) Bactericidal action of binary and ternary mixtures of carvacrol, thymol, and eugenol against Listeria innocua. J Food Sci 76: M95-100.

15. Santiesteban-López A, Palou E, López-Malo A (2007) Susceptibility of foodborne bacteria to binary combinations of antimicrobials at selected $a(w)$ and pH. J Appl Microbiol 102: 486-497.

16. Michiels JMJ, Fremaut D, De Smet S, Dierick N (2007) In vitro dose-response of carvacrol, thymol, eugenol and trans-cinnamaldehyde and interaction of combinations for the antimicrobial activity against the pig gut flora. Livestock Science 109: 157-160.

17. Pei RS, Zhou F, Ji BP, Xu J (2009) Evaluation of combined antibacterial effects of eugenol, cinnamaldehyde, thymol, and carvacrol against $E$. coli with an improved method. J Food Sci 74: M379-383.

18. Sabulal B, Dan M, J AJ, Kurup R, Pradeep NS, et al. (2006) Caryophyllene-rich rhizome oil of Zingiber nimmonii from South India: Chemical characterization and antimicrobial activity. Phytochemistry 67: 2469-2473.

19. Friedman M, Buick R, Elliott CT (2004) Antibacterial activities of naturally occurring compounds against antibiotic-resistant Bacillus cereus vegetative cells and spores, Escherichia coli, and Staphylococcus aureus. J Food Prot 67: 1774-1778.

20. Gaysinsky S, Davidson PM, McClements DJ, Weiss J (2007) Formulation and characterization of phytophenol-carrying antimicrobial microemulsions. Food Biophysics 3: 54-65.

21. Ghosh V, Mukherjee A, Chandrasekaran N (2014) Eugenol-loaded antimicrobial nanoemulsion preserves fruit juice against, microbial spoilage. Colloids Surf B Biointerfaces 114: 392-397.

22. Hamed SF, Sadek Z, Edris A (2012) Antioxidant and antimicrobial activities of clove bud essential oil and eugenol nanoparticles in alcohol-free microemulsion. J Oleo Sci 61: 641-648.

23. Rocha- Filho PA, Camargo MFP, Ferrari M, Maruno M (2014) Influence of Lavander Essential Oil Addition on Passion Fruit Oil Nanoemulsions: Stability and In vivo Study. J Nanomed Nanotechnol 5: 198.

24. Terjung N, Löffler M, Gibis M, Hinrichs J, Weiss J (2012) Influence of droplet size on the efficacy of oil-in-water emulsions loaded with phenolic antimicrobials. Food Funct 3: 290-301.

25. Ziani K, Chang Y, McLandsborough L, McClements DJ (2011) Influence of surfactant charge on antimicrobial efficacy of surfactant-stabilized thyme oil nanoemulsions. J Agric Food Chem 59: 6247-6255.

26. Gaysinsky S, Taylor TM, Davidson PM, Bruce BD, Weiss J (2007) Antimicrobial efficacy of eugenol microemulsions in milk against Listeria monocytogenes and Escherichia coli O157:H7. J Food Prot 70: 2631-2637.

27. Pérez-Conesa D, McLandsborough L, Weiss J (2006) Inhibition and inactivation of Listeria monocytogenes and Escherichia coli 0157: $\mathrm{H} 7$ colony biofilms by micellar-encapsulated eugenol and carvacrol. J Food Prot 69: 2947-2954.

28. Chen F, Shi Z, Neoh KG, Kang ET (2009) Antioxidant and antibacterial activities of eugenol and carvacrol-grafted chitosan nanoparticles. Biotechnol Bioeng 104: 30-39.

29. El-Shahaby O, El-Zayat M, Salih E, El-Sherbiny IM, Reicha FM (2013) Evaluation of Antimicrobial Activity of Water Infusion Plant-Mediated Silver Nanoparticles. J Nanomed Nanotechol 4: 178

30. Gomes C, Moreira RG, Castell-Perez E (2011) Poly (DL-lactide-co-glycolide) (PLGA) nanoparticles with entrapped trans-cinnamaldehyde and eugenol for antimicrobial delivery applications. J Food Sci 76: N16-24.
31. Iannitelli A, Grande R, Di Stefano A, Di Giulio M, Sozio P, et al. (2011) Potential Antibacterial Activity of Carvacrol-Loaded Poly(DL-lactide-co-glycolide) (PLGA) Nanoparticles against Microbial Biofilm. Int J Mol Sci 12: 5039-5051.

32. Keawchaoon L, Yoksan R (2011) Preparation, characterization and in vitro release study of carvacrol-loaded chitosan nanoparticles. Colloids Surf B Biointerfaces 84: 163-171.

33. Parris N, Cooke PH, Hicks KB (2005) Encapsulation of essential oils in zein nanospherical particles. J Agric Food Chem 53: 4788-4792.

34. Sanpui P, Murugadoss A, Prasad PV, Ghosh SS, Chattopadhyay A (2008) The antibacterial properties of a novel chitosan-Ag-nanoparticle composite. Int J Food Microbiol 124: 142-146

35. Singh K, Panghal M, Kadyan S, Chaudhary U, Yadav JP (2014) Antibacteria Activity of Synthesized Silver Nanoparticles from Tinospora cordifolia against Multi Drug Resistant Strains of Pseudomonas aeruginosa Isolated from Burn Patients. J Nanomed Nanotechnol 5: 192

36. Wu YP, Luo YG, Wang Q (2012) Antioxidant and antimicrobial properties of essential oils encapsulated in zein nanoparticles prepared by liquid-liquid dispersion method. Lwt-Food Science and Technology 48: 283-290.

37. Huynh NT, Passirani C, Saulnier P, Benoit JP (2009) Lipid nanocapsules: a new platform for nanomedicine. Int J Pharm 379: 201-209.

38. Heurtault B, Saulnier P, Pech B, Proust JE, Benoit JP (2002) A novel phase inversion-based process for the preparation of lipid nanocarriers. Pharm Res 19: $875-80$.

39. Fadli M, Saad A, Sayadi S, Chevalier J, Mezrioui NE, et al. (2011) Antibacterial activity of Thymus maroccanus and Thymus broussonetii essential oils agains nosocomial infection - bacteria and their synergistic potential with antibiotics. Phytomedecine 19: 464-471.

40. Morille M, Montier T, Legras P, Carmoy N, Brodin P, et al. (2010) Long circulating DNA lipid nanocapsules as new vector for passive tumor targeting Biomaterials 31: 321-329.

41. Helander HLA, Kyösti LK, Tiina MS, Irene P, Smid EJ, et al. (1998) Characterization of the Action of Selected Essential Oil Components on GramNegative Bacteria. Journal of agricultural and food chemistry 46: 3590-3595.

42. Gill AO, Holley RA (2006) Disruption of Escherichia coli, Listeria monocytogenes and Lactobacillus sakei cellular membranes by plant oil aromatics. Int J Food Microbiol 108: 1-9.

43. Ultee A, Bennik MH, Moezelaar R (2002) The phenolic hydroxyl group of carvacrol is essential for action against the food-borne pathogen Bacillus cereus. Appl Environ Microbiol 68: 1561-1568.

44. Kempf MEM, Kowalczyk F, Rossines E, Panhelleux G, Joly-Guillou ML (2011) Study of the sensitivity of 224 bacteria isolated from hospital infections vis-a-vis the JCA JCA 250 and 251 compounds from essential oils from research Aroma Technologies. Study of Biology sePathologie 59: 39-73.

45. Vonarbourg A, Passirani C, Saulnier P, Simard P, Leroux JC, et al. (2006) Evaluation of pegylated lipid nanocapsules versus complement system activation and macrophage uptake. J Biomed Mater Res A 78: 620-628.

46. Fu Y, Zu Y, Chen L, Shi X, Wang Z, et al. (2007) Antimicrobial activity of clove and rosemary essential oils alone and in combination. Phytother Res 21: 989 994.

47. Hill Laura E, Gomes C, Matthew TT (2013) Characterization of beta-cyclodextrin inclusion complexes containing essential oils (trans-cinnamaldehyde, eugenol, cinnamon bark and clove bud extracts) for antimicrobial delivery applications. LWT - Food Science and Technology 51: 86-93.

48. Ben Arfa A, Combes S, Preziosi-Belloy L, Gontard N, Chalier P (2006) Antimicrobial activity of carvacrol related to its chemical structure. Lett App Microbiol 43: 149-154.

49. Lambert RJ, Skandamis PN, Coote PJ, Nychas GJ (2001) A study of the minimum inhibitory concentration and mode of action of oregano essential oil thymol and carvacrol. J Appl Microbiol 91: 453-462.

50. Joly-Guillou ML (2005) Clinical impact and pathogenicity of Acinetobacter. Clin Microbiol Infect 11: 868-873.

51. Wolff M, Joly-Guillou ML, Farinotti R, Carbon C (1999) In vivo efficacies of combinations of beta-lactams, beta-lactamase inhibitors, and rifampin against Acinetobacter baumannii in a mouse pneumonia model. Antimicrob Agents Chemother 43: 1406-1411. 
Citation: Montagu A, Saulnier P, Cassissa V, Rossines E, Eveillard M, et al. (2014) Aromatic and Terpenic Compounds Loaded in Lipidic Nanocapsules: Activity against Multi-drug Resistant Acinetobacter baumannii Assessed in vitro and in a Murine Model of Sepsis. J Nanomed Nanotechnol 5: 206. doi: 10.4172/2157-7439.1000206

52. Ballot $S$, Noiret N, Hindré F, Denizot B, Garin E, et al. (2006) $99 \mathrm{mTc} / 188 R e-$ labelled lipid nanocapsules as promising radiotracers for imaging and therapy: formulation and biodistribution. Eur J Nucl Med Mol Imaging 33: 602-607.

53. Morille M, Montier T, Legras P, Carmoy N, Brodin P, et al. (2010) Longcirculating DNA lipid nanocapsules as new vector for passive tumor targeting Biomaterials 31: 321-329

54. Ghosh S, Patil S, Ahire M, Kitture R, Kale S, et al. (2012) Synthesis of silver nanoparticles using Dioscorea bulbifera tuber extract and evaluation of its synergistic potential in combination with antimicrobial agents. Int $\mathrm{J}$ Nanomedicine 7: 483-496.
55. Huang L, Dai T, Xuan Y, Tegos GP, Hamblin MR (2011) Synergistic combination of chitosan acetate with nanoparticle silver as a topical antimicrobial: efficacy against bacterial burn infections. Antimicrob Agents Chemother 55: 3432-3438.

56. Rhim JW, Hong SI, Park HM, Ng PK (2006) Preparation and characterization of chitosan-based nanocomposite films with antimicrobial activity. J Agric Food Chem 54: 5814-5822.

57. Mihu MR, Sandkovsky U, Han G, Friedman JM, Nosanchuk JD, et al. (2010) The use of nitric oxide releasing nanoparticles as a treatment against $A$ cinetobacter baumannii in wound infections. Virulence 1: 62-67.
Citation: Montagu A, Saulnier P, Cassissa V, Rossines E, Eveillard M, et al. (2014) Aromatic and Terpenic Compounds Loaded in Lipidic Nanocapsules: Activity against Multi-drug Resistant Acinetobacter baumannii Assessed in vitro and in a Murine Model of Sepsis. J Nanomed Nanotechnol 5: 206. doi: $10.4172 / 2157-7439.1000206$
Submit your next manuscript and get advantages of OMICS Group submissions

Unique features:

- User friendly/feasible website-translation of your paper to 50 world's leading languages

Audio Version of published paper

Digital articles to share and explore

Special features:

- 350 Open Access Journals

30,000 editorial team

21 days rapid review process

- Quality and quick editorial, review and publication processing

- Indexing at PubMed (partial), Scopus, EBSCO, Index Copernicus and Google Scholar etc

- Sharing Option: Social Networking Enabled

- Authors, Reviewers and Editors rewarded with online Scientific Credits

- Better discount for your subsequent articles

Submit your manuscript at: www.editorialmanager.com/biochem 